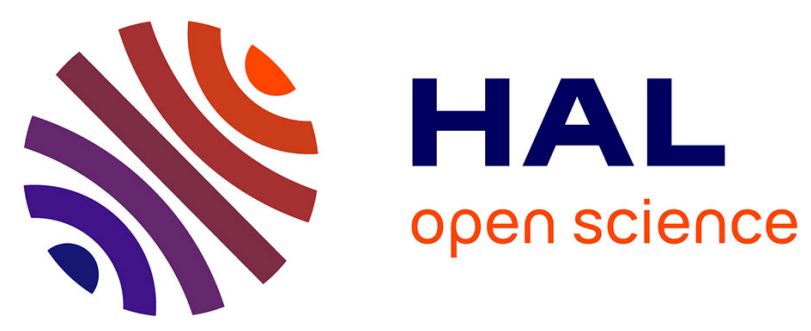

\title{
On Multivariate Prudence
}

Elyès Jouini, Clotilde Napp, Diego Nocetti

\section{To cite this version:}

Elyès Jouini, Clotilde Napp, Diego Nocetti. On Multivariate Prudence. Journal of Economic Theory, 2013, 148 (3), pp.1255-1267. 10.1016/j.jet.2012.10.007 . halshs-00635558

\section{HAL Id: halshs-00635558 https://shs.hal.science/halshs-00635558}

Submitted on 25 Oct 2011

HAL is a multi-disciplinary open access archive for the deposit and dissemination of scientific research documents, whether they are published or not. The documents may come from teaching and research institutions in France or abroad, or from public or private research centers.
L'archive ouverte pluridisciplinaire HAL, est destinée au dépôt et à la diffusion de documents scientifiques de niveau recherche, publiés ou non, émanant des établissements d'enseignement et de recherche français ou étrangers, des laboratoires publics ou privés. 


\title{
On Multivariate Prudence
}

\author{
Elyès Jouini \\ Clotilde Napp \\ Diego Nocetti \\ Ceremade \\ CNRS-DRM \\ Clarkson University \\ July 19, 2011
}

\begin{abstract}
In this paper we extend the theory of precautionary saving to the case in which uncertainty is multidimensional and we develop a matrix-measure of multivariate prudence. Furthermore, we characterize comparative prudence, decreasing and increasing prudence, the effect of uncertainty on the marginal propensity to consume out of wealth, and the Drèze-Modigliani substitution effect in this multivariate setting. We also characterize the concept of multivariate downside risk aversion as a multivariate preference for harm disaggregation. We show that our definition is equivalent to a positive precautionary saving motive. We propose an alternative measure of the intensity of downside risk aversion and show that this measure is useful in understanding several economic problems that involve multivariate preferences.
\end{abstract}

\section{Introduction}

It has been known since Leland (1968) and Sandmo (1970) that a positive third derivative of a von-Neumann-Morgenstern utility function is equivalent to a precautionary saving motive; that is, an increase in saving in response to the presence of uncertainty surrounding future income. Kimball (1990b) gave the name prudence to the sensitivity of optimal saving to risk and proposed the index of prudence, $\frac{-v^{\prime \prime \prime}(x)}{v^{\prime \prime}(x)}$, as a measure of this sensitivity. This measure is isomorphic to Pratt (1964) and Arrow (1971)'s index of risk aversion, $\frac{-v^{\prime \prime}(x)}{v^{\prime}(x)}$, which measures how much a given person dislikes risk. Just as the Arrow-Pratt index of risk aversion implies that a more risk averse individual will require a higher risk premium 
to remain indifferent in the presence of a fair risk, Kimball's index implies that a more prudent person will require a larger precautionary saving premium to remain indifferent in the presence of a fair risk (i.e. requires a larger increase in income to save the same amount as in the absence of the risk).

Despite the tremendous usefulness of these measures in many contexts, one of their drawbacks is that they can only be applied to situations in which utility is a function of one variable (e.g. income). Recognizing the limitations that such approach entails, a number of authors have extended the Arrow-Pratt theory of risk aversion to the case in which utility depends on many attributes and the risk is multi-dimensional [e.g. Stiglitz (1969), Kihlstrom and Mirman (1974), Paroush (1975), Duncan (1977), Karni (1979)]. Karni (1979), in particular, proposed a matrix-measure of risk aversion and studied the conditions under which a multivariate utility function is more risk averse than another. To the best of our knowledge, there does not exist in the literature a measure that captures the sensitivity of saving to a multidimensional risk. The first objective of this paper is to present such a measure of multivariate prudence and to study its properties.

Just as Kimball (1990b) established the isomorphism between prudence and risk aversion in the case of a univariate utility function, we provide a mapping of Karni's (1979) results on multivariate risk aversion to the case of multivariate prudence. Specifically, we derive a matrix-measure of multivariate prudence and we relate it to the properties of the precautionary saving premium for both small and large multidimensional risks. We establish, in particular, that given a multidimensional risk 1) the precautionary saving premium is positive if, and only if, our multivariate matrix-measure is positive semi-definite and 2) given two multivariate utility functions, the precautionary saving premium is larger for that utility for which our multivariate measure is larger (in the sense that the difference is positive semi-definite). The measure that we propose also allows us to characterize increasing and decreasing prudence, the effect of uncertainty on the marginal propensity to consume out of wealth, and the Drèze-Modigliani (1972) substitution effect in a multivariate setting. In this way, our work both extends and complements not only the results of Kimball (1990 a,b) but also more recent work [Courbage and Rey (2007), Eeckhoudt et al. (2007), Menegatti (2009), Nocetti and Smith (2011 a,b), Denuit et al. (2011)] that establishes conditions for precautionary saving to occur in the context of bi-variate utility functions.

A concept that is closely related to Kimball's notion of prudence is that of downside risk aversion [Menezes et al. (1980), Eeckhoudt and Schlesinger (2006)]. An individual is said to be downside risk averse if he prefers to locate an addi- 
tional risk in states of nature in which wealth is high rather than in states of nature in which wealth is low. It is by now well known that, in an expected utility univariate framework, downside risk aversion is equivalent to a positive third derivative of the utility function, so it is also equivalent to a positive precautionary saving motive. We propose an analogous characterization of a preference for harm disaggregation for the case in which the risk is multidimensional. In particular, we define the concept of multivariate downside risk aversion (MDRA) as a preference over lotteries in which the multidimensional risk is present when the level of the attributes is high rather than when the level of the attributes is low. We show that, in an expected utility framework, our definition is equivalent to a positive precautionary saving motive. That is, an individual that displays MDRA (or equivalently, multivariate prudence) endogenously selects to mitigate the pain caused by the multidimensional risk by transferring current resources to the future. ${ }^{1}$

Despite the equivalency of downside risk aversion and a positive precautionary saving motive many authors have convincingly proposed to measure the intensity of downside risk aversion with a different function than Kimball's (1990) measure of prudence. Crainich and Eeckhoudt (2008), for example, suggested to measure the intensity of downside risk aversion with the function $\frac{v^{\prime \prime \prime}(x)}{v^{\prime}(x)}$ [see also Modica and Scarsini (2005), Jindapon and Neilson (2007), and Denuit and Eeckhoudt (2010)]. Following these lines, we propose an alternative matrix measure that captures the intensity of MDRA. We show that this measure is useful for evaluating a number of economic problems, including the problem of social discounting when social preferences are multidimensional and the problem of saving in the presence of multidimensional rate of return risk.

The rest of the paper is structured as follows. In Section 2 we begin by presenting the model of precautionary saving with multiple sources of risk and we provide a number of interpretations for the problem. Then, we characterize multivariate prudence and define the precautionary premium (Section 2.2), we derive the matrix measure of multivariate prudence from the local approximation of the precautionary premium (Section 2.3), and we show that this measure is appropriate for comparing precautionary saving attitudes among consumers (Section 2.4). Next, we define the notion of increasing and decreasing prudence and we

\footnotetext{
${ }^{1}$ In this way, our characterization also complements the work of Eeckhoudt et al. (2007), who linked a precautionary saving motive with a preference for harm disaggregation (which they called cross prudence) in the context of a bivariate utility function and a single source of risk.
} 
show its connection with the response of the marginal propensity to consume to the presence of a multidimensional risk (Section 2.5), we present a multivariate version of the Drèze-Modigliani substitution effect (Section 2.6), and we present a few specific examples of our results (Section 2.7). In Section 3 we begin by defining MDRA and by showing that precautionary saving with multiple sources of risk can be interpreted as endogenous disaggregation of harms. Then, we derive a measure of the intensity of MDRA (Section 3.2) and present the abovementioned applications (Section 3.3). Section 4 concludes while Section 5 presents the lengthier proofs of our results.

\section{Precautionary Saving with Multi-dimensional Risks}

\subsection{Setup and motivation}

As is standard in the univariate theory of precautionary saving we consider a model with 2 dates $^{2}$. As opposed to the standard analysis, we assume that the consumer derives utility from $n+1$ attributes, $\left(x_{0}, x_{1}, \ldots, x_{n}\right)$, one of them, $x_{0}$, being the income. Many interpretations for the other variables are possible. They include, but are not limited to, the following:

- A vector of market prices. In this case the period utility function can be interpreted as the indirect utility given the optimal allocation across the commodities. This is the interpretation given by Karni (1979) in the context of risk aversion ${ }^{3}$.

- Similarly, in a model where consumption and leisure enter the utility function and labor supply is endogenous, indirect utility will be a function of income (wages, non-labor income, and savings) and the relative price of leisure (wages) ${ }^{4}$.

\footnotetext{
${ }^{2}$ See, for example, Leland (1968), Sandmo (1970), Drèze and Modigliani (1972), Kimball (1990), Eeckhoud and Schlesinger (2008), Kimball and Weil (2009). See Carroll and Kimball (2008) for a recent review of the theoretical and empirical literature on (univariate) precautionary saving.

${ }^{3}$ Nocetti and Smith (2011a) develop an infinite horizon model of precautionary saving with commodity price uncertainty. They study the particular case of Cobb-Douglas utility.

${ }^{4}$ Within this framework, Nocetti and Smith (2011b) establish conditions for precautionary saving to occur under the assumption of homothetic preferences over consumption and leisure. Also within this framework, Floden (2006) evaluates the case of small labor income risks.
} 
- Non-traded commodities, such as the individual's health status, environmental quality, and public goods ${ }^{5}$.

- Characteristics of other individuals that affect the consumer's welfare. For example, the consumer may derive utility from the income, health, or education of other members of the family and or of society ${ }^{6}$.

- Own characteristics in the view of others, i.e. social recognition, in which case the attributes may represent the opinion of others ${ }^{7}$.

- Own characteristics relative to the characteristics of others. For example, the attributes may represent absolute or relative differences of the consumer's income with respect to the income of her/his neighbors or with respect to the average income in society ${ }^{8}$.

In the first period our consumer saves an amount $s$ of his income. For generality, we will not restrict the return on saving to affect only future income. Instead, we consider the case in which the rate of return on saving for attribute $i$ $(i=0,1, \ldots, n)$ is $\rho_{i}$. We will denote by $\rho$ the vector $\rho=\left(\rho_{0}, \rho_{1}, \ldots, \rho_{n}\right)$. For example, the consumer may spend current resources to improve his future health, his relative status in society, and or other individuals' opinions about him (e.g. these two latter aspects capture Veblen's (1899) notion of conspicuous consumption). This setup also permits to model the fact that reducing current consumption might have a positive impact on future environmental quality. Furthermore, in the case of public goods, this can capture private contributions to different public

\footnotetext{
${ }^{5}$ This is the interpretation of Courbage and Rey (2007), Menegatti (2009), and Denuit et al. (2011), who provide conditions for precautionary saving to occur in a bi-variate framework. Eeckhoudt et al. (2007) provide an interpretation to these conditions within the context of simple bi-variate lotteries.

${ }^{6}$ The fact that an individual's welfare may depend on characteristics of other individuals has a long tradition. Bentham (1789 ch.5), for example, described the 'pleasure of benevolence or social affection' as "the pleasures resulting from the view of any pleasures supposed to be possessed by the beings who may be the objects of benevolence." Becker (1974) adopts these ideas to develop a theory of social interactions.

${ }^{7}$ Bentham (1789), for example, described the 'pleasure of a good name' as "the pleasures that accompany the persuasion of a man's being in the acquisition or the possession of the good-will of the world about him."

${ }^{8}$ This is the idea of "keeping up with the Joneses," studied formally in the context of saving by Duesenberry (1949) and more recently by Abel (1990) and Gali (1994) in the context of asset pricing.
} 
goods. Finally, this may capture transfers, bequests, and charitable contributions to other individuals whose welfare affects the consumer's own welfare (see, e.g., Becker (1974)).

The consumer is endowed with increasing (with respect to each attribute) and concave utility functions $u$ and $v$ that respectively measure the contribution of date 0 and date 1 consumption plans $X_{0}=\left(x_{00}, x_{01}, \ldots, x_{0 n}\right)$ and $X_{1}=\left(x_{10}, x_{11}, \ldots, x_{1 n}\right)$ to the total utility. We assume that $u$ satisfies the Inada condition with respect to its first variable, that is to say $\lim _{x_{00} \rightarrow-\infty} \frac{\partial u}{\partial x_{0}}\left(X_{0}\right)=\infty$ and $\lim _{x_{00} \rightarrow \infty} \frac{\partial u}{\partial x_{0}}\left(X_{0}\right)=0$ where $\left(x_{01}, \ldots, x_{0 n}\right)$ are kept fixed.

For each $i$ such that $\rho_{i} \neq 0$, we also assume that $v$ satisfies a uniform Inada condition with respect to $x_{i}$, that is to say $\lim _{x_{1 i} \rightarrow-\infty} \frac{\partial v}{\partial x_{i}}\left(X_{1}\right)=\infty$ where the convergence is uniform with respect to $X_{1,-i}$ that corresponds to the vector $X_{1}$ deprived of its $i^{\text {th }}$ coordinate and $\lim _{x_{1 i} \rightarrow \infty} \frac{\partial v}{\partial x_{i}}\left(X_{1}\right)=0$ where the convergence is uniform with respect to $X_{1,-i}$ on $[k, \infty)$ for some $k$. When $v$ is interpreted as an indirect utility function where $x_{10}$ is a wealth variable and where $\left(x_{11}, \ldots, x_{1 n}\right)$ are price variables, it is natural to assume that $\rho_{i}=0, i=1, \ldots, n$, and the Inada condition is then only on $\frac{\partial v}{\partial x_{0}}$.

In the next, we will denote by $\delta$ the vector $(1,0, \ldots, 0)$.

\subsection{Multivariate prudence and the equivalent precautionary premium}

Under certainty, the consumption/saving problem is

$$
\arg \max _{s} h(s)
$$

with

$$
h(s)=u\left(X_{0}-s \delta\right)+v\left(X_{1}+s \rho\right) .
$$

We have

$$
h^{\prime}(s)=-\frac{\partial u}{\partial x_{0}}\left(X_{0}-s \delta\right)+\sum_{i=0}^{n} \rho_{i} \frac{\partial v}{\partial x_{i}}\left(X_{1}+s \rho\right)
$$

and, by Inada condition on $u$ we have $\lim _{s \rightarrow \infty}-\frac{\partial u}{\partial x_{0}}\left(X_{0}-s \delta\right)=-\infty$ and $\lim _{s \rightarrow-\infty}-\frac{\partial u}{\partial x_{0}}\left(X_{0}-s \delta\right)=0$. For $i$ such that $\rho_{i} \neq 0$ and by the uniform Inada condition on $v$, we have $\lim _{s \rightarrow \infty} \frac{\partial v}{\partial x_{i}}\left(X_{1}+s \rho\right)=0$ and $\lim _{s \rightarrow-\infty} \frac{\partial v}{\partial x_{i}}\left(X_{1}+s \rho\right)=$ $\infty$. We have then $\lim _{s \rightarrow-\infty} h^{\prime}(s)=\infty$ and $\lim _{s \rightarrow \infty} h^{\prime}(s)=-\infty$. There exists then $s^{*}$ such that $h^{\prime}\left(s^{*}\right)=0$ and since $h$ is concave, $s^{*}$ solves the consumption/saving problem (2.1). It is easy to verify that the optimal solution $s^{*}$ is increasing in $x_{00}$; 
that is to say, the optimal saving level is increasing in the level of income at date 0 . In the next, we assume that the optimal solution is decreasing in $x_{10}$; that is to say, the optimal saving level decreases with the date 1 income, which seems to be a natural assumption. This is equivalent to imposing that

$$
-\frac{-\frac{\partial}{\partial x_{0}} \sum_{i=0}^{n} \rho_{i} \frac{\partial v}{\partial x_{i}}\left(X_{1}+s^{*} \rho\right)}{-\frac{\partial^{2} u}{\partial x_{0}^{2}}\left(X_{0}-s^{*} \delta\right)-\sum_{i, j=0}^{n} \rho_{i} \rho_{j} \frac{\partial^{2} v}{\partial x_{i}^{2}}\left(X_{1}+s^{*} \rho\right)}<0 .
$$

Since $u$ and $v$ are concave, the denominator is positive and our condition can be rewritten as follows

$$
\frac{\partial}{\partial x_{0}} \sum_{i=0}^{n} \rho_{i} \frac{\partial v}{\partial x_{i}}\left(X_{1}+s^{*} \rho\right)<0, \text { for all } X_{0}, X_{1} \in \mathbb{R}^{n+1} .
$$

This last condition is immediately satisfied if we assume that

$$
\frac{\partial w}{\partial x_{0}}\left(X_{1}\right)<0, \text { for all } X_{1} \in \mathbb{R}^{n+1}
$$

where $w\left(X_{1}\right)=\sum_{i=0}^{n} \rho_{i} \frac{\partial v}{\partial x_{i}}\left(X_{1}\right)$. Conversely, let us assume that (2.2) is satisfied and let us consider a given $X_{1}$. By Inada conditions, there exists $X_{0}$ such that $\frac{\partial u}{\partial x_{0}}\left(X_{0}\right)=\sum \rho_{i} \frac{\partial v}{\partial x_{i}}\left(X_{1}\right)$. By construction, the optimal saving level associated to $\left(X_{0}, X_{1}\right)$ is given by $s^{*}=0$. By $(2.2)$, we then have $\frac{\partial w}{\partial x_{0}}\left(X_{1}\right)<0$. Condition $(2.2)$ is then equivalent to $(2.3)$. In the next, we let $w_{i} \equiv \frac{\partial w}{\partial x_{i}}$ and $w_{i j} \equiv \frac{\partial w}{\partial x_{i} \partial x_{j}}$; by $(2.3)$ we have $w_{0}<0$.

Let us now consider the case where there is uncertainty at date 1 . Throughout the paper, uncertainty will be described as follows. We assume that the date 1 consumption vector $X_{1}$ might be affected by a noise $\widetilde{e}=\left(\widetilde{e}_{0}, \widetilde{e}_{1}, \ldots, \widetilde{e}_{n}\right)$ such that $E\left[\widetilde{e}_{i}\right]=0, i=0, \ldots, n$, and with a variance-covariance matrix $V^{e} \equiv\left[\sigma_{i j}\right]$ with $\sigma_{i j}=\operatorname{cov}\left(\widetilde{e}_{i}, \widetilde{e}_{j}\right)$. We denote by $\widetilde{X}_{1}=\left(\widetilde{x}_{10}, \widetilde{x}_{11}, \ldots, \widetilde{x}_{1 n}\right)$ the vector of date 1 noisy consumption $\widetilde{X}_{1}=X_{1}+\widetilde{e}=\left(x_{10}+\widetilde{e}_{0}, \ldots, x_{1 n}+\widetilde{e}_{n}\right)$.

The consumption/saving problem becomes

$$
\arg \max _{s} H(s)
$$

with

$$
H(s)=u\left(X_{0}-s \delta\right)+E\left[v\left(\widetilde{X}_{1}+s \rho\right)\right],
$$

The solution is denoted by $\widehat{s}$ and characterized by $H^{\prime}(\widehat{s})=0$.

Our objective is to compare $\widehat{s}$ with $s^{*}$. In the spirit of Kimball (1990b) we propose the following definition 
Definition 1. An individual is multivariate prudent if the multidimensional risk $\widetilde{e}$ generates precautionary saving, i.e., $\widehat{s} \geq s^{*}$.

Since $u$ and $v$ are concave, the function $H^{\prime}$ is decreasing and the optimal saving $\widehat{s}$ is greater than $s^{*}$ if and only if $H^{\prime}\left(s^{*}\right) \geq 0$. We have

$$
H^{\prime}\left(s^{*}\right)=-\frac{\partial u}{\partial x_{0}}\left(X_{0}-s^{*} \delta\right)+E\left[w\left(\widetilde{X}_{1}+s^{*} \rho\right)\right],
$$

and since $\frac{\partial u}{\partial x_{0}}\left(X_{0}-s^{*} \delta\right)=w\left(X_{1}+s^{*} \rho\right)$

$$
H^{\prime}\left(s^{*}\right)=-w\left(X_{1}+s^{*} \rho\right)+E\left[w\left(\widetilde{X}_{1}+s^{*} \rho\right)\right]
$$

and $H^{\prime}\left(s^{*}\right) \geq 0$ if and only if

$$
E\left[w\left(\tilde{X}_{1}+s^{*} \rho\right)\right] \geq w\left(X_{1}+s^{*} \rho\right) .
$$

Since we want this inequality to hold for any value of $X_{1}$, and any additional risk $\widetilde{e}$ and since $X_{0}$ is arbitrary, we want $E[w(\widetilde{X})] \geq w(X)$ for all random variable $\widetilde{X}$. By Equation (2.3), the function $w$ being decreasing in its first variable, we introduce the equivalent precautionary premium $\Psi(X, \widetilde{e}, w)$ defined by

$$
\Psi(X, \widetilde{e}, w)=\inf \{\psi: E[w(\tilde{X})] \leq w(X-\psi \delta)\}
$$

Since $\lim _{\Psi \rightarrow \infty} w(X-\psi \delta)=\infty$, the equivalent precautionary premium is well defined and lies in $\mathbb{R} \cup\{-\infty\}$. When $\Psi(X, \widetilde{e}, w)$ is finite, we have $E[w(\tilde{X})]=$ $w(X-\Psi(X, \widetilde{e}, w) \delta)$ and $\Psi(X, \widetilde{e}, w)$ then corresponds to the certain reduction in income at date 1 that has the same upward impact on the optimal saving as the introduction of the additional risk $\widetilde{e}$.

\subsection{Local approximation of the equivalent precautionary premium}

From now on we only deal with date 1 utility functions and with date 1 allocations. For simplicity of notations, we will denote by $X=\left(x_{0}, x_{1}, \ldots, x_{n}\right)$ a date 1 allocation instead of $X_{1}=\left(x_{10}, x_{11}, \ldots, x_{1 n}\right)$. We will further assume that $\Psi(X, \widetilde{e}, w)$ is finite (in the next we sometimes just denote it by $\Psi$ ). By Taylor expansions of the functions on both sides of (2.5), we have

$$
w(X-\Psi \delta)=w(X)-\Psi w_{0}(X)+O\left(\Psi^{2}\right)
$$


and

$$
\begin{aligned}
E[w(\widetilde{X})] & =w(X)+E\left[\sum_{i=0}^{n} w_{i}(X) \widetilde{e}_{i}\right]+E\left[\frac{1}{2} \sum_{i=0}^{n} \sum_{j=0}^{n} w_{i j}(X) \widetilde{e}_{i} \widetilde{e}_{j}\right]+o\left(\operatorname{tr} V^{e}\right) \\
& =w(X)+\frac{1}{2} \sum_{i=0}^{n} \sum_{j=0}^{n} w_{i j}(X) \sigma_{i j}+o\left(\operatorname{tr} V^{e}\right)
\end{aligned}
$$

Setting these expressions equal to one another, as required by (2.5), we obtain a local approximation of $\Psi$

$$
-\Psi w_{0}(X) \approx \frac{1}{2} \sum_{i=0}^{n} \sum_{j=0}^{n} w_{i j}(X) \sigma_{i j}
$$

hence

$$
\Psi \approx-\frac{1}{2} \sum_{i=0}^{n} \sum_{j=0}^{n} \frac{w_{i j}(X)}{w_{0}(X)} \sigma_{i j}
$$

Letting $P^{w}$ denote the matrix $P^{w} \equiv\left[-\frac{w_{i j}}{w_{0}}\right]$, we have

$$
\Psi(X, \widetilde{e}, w) \approx \frac{1}{2} \operatorname{tr}\left[V^{e} P^{w}(X)\right]
$$

$P^{w}$ is our matrix-measure of local multivariate prudence. The diagonal elements of $P^{w}, \frac{-w_{j j}}{w_{0}}$, capture the precautionary premium per unit of variance when each risk is taken in isolation. For example, if $\rho_{i}=0$ for $i=1,2, \ldots, n$ the first element of $P^{w}$ is Kimball's measure of prudence, $\frac{-w_{00}}{w_{0}}=\frac{-v_{000}}{v_{00}}$. Similarly, each of the other diagonal elements of $P^{w}$ can be interpreted as measures of cross-prudence (Eeckhoudt and Schlesinger, 2007). The off-diagonal elements, $\frac{-w_{i j}}{w_{0}}$, can be interpreted as the excess precautionary saving premium per unit of covariance. They capture the distaste for positive dependence between two attributes, which the consumer compensates with extra saving.

The next proposition points out an important (global) property of $P^{w}$ relative to $\Psi$.

Proposition 1. The following conditions are equivalent:

1. The function $w$ is convex in $X$. 
2. The precautionary premium is nonnegative, $\Psi(X, \widetilde{e}, w) \geq 0, \forall X, \forall \widetilde{e}$.

3. The matrix $P^{w}(X)$ is positive semi-definite for all $(X)$.

Proof $(1) \Leftrightarrow(3)$ : The function $w$ is convex if and only if the matrix $H \equiv\left[w_{i j}\right]$ is positive semi-definite. Since $P^{w}=-\frac{1}{w_{0}} H$ and $-\frac{1}{w_{0}}>0$, we have that $w$ is convex if and only if the matrix $P^{w}$ is positive semi-definite.

$(1) \Leftrightarrow(2)$ : The function $w$ is convex if and only if $E[w(\widetilde{X})] \geq w(X), \forall X, \forall \widetilde{e}$ or equivalently if and only if $\Psi(X, \widetilde{e}, w) \geq 0, \forall X, \forall \widetilde{e}$.

The property that the precautionary premium is positive if, and only if, our measure of multivariate prudence is positive is an important one. However, possibly more important is establishing if our measure can be used for comparing optimal decisions of individuals with different preferences. This is the topic of the next section.

\subsection{Comparative multivariate prudence in the small and in the large}

In the classical article "Risk Aversion in the Small and in the Large", Pratt (1964) established the close relationship between the intensity of risk aversion and the size of the risk premium, for both small and large unidimensional risks. In particular, given two individuals, say $A$ and $B$, with a degree of risk aversion $a_{A}$ and $a_{B}$ respectively, $A$ will require a larger risk premium than $B$ to remain indifferent in the presence of a small or large risk if, and only if, $a_{A}>a_{B}$. In a similar fashion, Kimball (1990b) established that, in the presence of a unidimensional risk, a person will require a larger precautionary saving premium than another if, and only if, he or she is more prudent. Karni (1979) extended Pratt's result to the case of multidimensional risks. Our objective now is to extend Kimball's result. For this purpose, we start with the following definition.

Definition 2. Agent $A$, with utility function $v_{A}$, is said more prudent than Agent $B$, with utility function $v_{B}$, if $\Psi\left(X, \widetilde{e}, w_{A}\right) \geq \Psi\left(X, \widetilde{e}, w_{B}\right), \forall X, \forall \widetilde{e}$, where $w_{A}(X)=$ $\sum_{i=0}^{n} \rho_{i} \frac{\partial v_{A}}{\partial x_{i}}(X)$ and $w_{B}(X)=\sum_{i=0}^{n} \rho_{i} \frac{\partial v_{B}}{\partial x_{i}}(X)$.

For small risks, the following proposition characterizes the fact that the precautionary premium $\Psi\left(X, \widetilde{e}, w_{A}\right)$ is higher than $\Psi\left(X, \widetilde{e}, w_{B}\right)$ in terms of $P^{w_{A}}(X)$ and $P^{w_{B}}(X)$.

Proposition 2. In the case of small risks $\widetilde{e}$, we have $\Psi\left(X, \widetilde{e}, w_{A}\right) \geq \Psi\left(X, \widetilde{e}, w_{B}\right)$ if and only if the matrix $\left[P^{w_{A}}-P^{w_{B}}\right](X)$ is positive semi-definite. 
Proof Suppose first that the matrix $\left[P^{w_{A}}-P^{w_{B}}\right](X)$ is positive semi-definite. In the case of small risks, we have, according to $(2.6), \Psi\left(X, \widetilde{e}, w_{A}\right)-\Psi\left(X, \widetilde{e}, w_{B}\right) \approx$ $\frac{1}{2} \operatorname{tr}\left[V^{e}\left(P^{w_{A}}-P^{w_{B}}\right)(X)\right] \geq 0$.

Suppose now that $\Psi\left(X, \widetilde{e}, w_{A}\right) \geq \Psi\left(X, \widetilde{e}, w_{B}\right)$. We then have

$$
\frac{1}{2} \operatorname{tr}\left[V\left(P^{w_{A}}-P^{w_{B}}\right)(X)\right] \geq 0
$$

for all positive semi-definite symmetric matrix $V$. Consider for a given vector $U$, the matrix $V \equiv U U^{t}$, then $U^{t}\left(P^{w_{A}}-P^{w_{B}}\right) U=\operatorname{tr}\left[U^{t}\left(P^{w_{A}}-P^{w_{B}}\right) U\right]=$ $\operatorname{tr}\left[V\left(P^{w_{A}}-P^{w_{B}}\right)\right] \geq 0$, hence $\left[P^{w_{A}}-P^{w_{B}}\right](X)$ is positive semi-definite.

Consider now the case of general risks. Since $w$ is continuous and monotone in $x_{0}$, we define the $\left(x_{1}, \ldots, x_{n}\right)$-inverse $w^{-1}\left(\cdot, x_{1, \ldots}, x_{n}\right)$ of $w$ as follows: $w\left(x_{0}, x_{1}, \ldots, x_{n}\right)=$ $y \Leftrightarrow w^{-1}\left(y, x_{1}, \ldots, x_{n}\right)=x_{0}$. We obtain the following global result, extending the result of Proposition 2 and relating the fact that one agent is more prudent than another to the matrices $P^{w_{A}}$ and $P^{w_{B}}$.

Proposition 3. The following three conditions are equivalent:

1. Agent $A$ is more prudent than agent $B$.

2. The function $\varphi\left(y, x_{1}, \ldots, x_{n}\right) \equiv w_{A}\left[w_{B}^{-1}\left(y, x_{1}, \ldots, x_{n}\right), x_{1}, \ldots, x_{n}\right]$ is convex in $\left(y, x_{1}, \ldots, x_{n}\right)$.

3. The matrix $R \equiv\left[P^{w_{A}}-P^{w_{B}}\right](X)$ is positive semi-definite $\forall X$.

Proof See Appendix.

We conclude that the intensity of the precautionary saving motive is unambiguously captured by the derived measure of multivariate prudence, for both small and large multidimensional risks.

At this point, a remark has to be made. Kihlstrom and Mirman (1974) proposed to restrict comparative multivariate risk aversion to the case in which the ordinal preferences of two individuals are identical. Within this context, person $A$ is said to be more risk averse than person $B$ if the (multivariate) utility of the former is a concave transformation of the latter. Karni (1979) showed, however, that the restriction of identical ordinal preference is not necessary as long as the comparison is based upon a particular choice of the risk premium. Yet, if ordinal preferences happen to be identical his matrix measure of risk aversion coincides with the definition of Kihlstrom and Mirman (1974). 
Similarly, our analysis of comparative prudence does not restrict ordinal preferences to be the same across individuals. As in the case of Karni's measure or risk aversion, our measure does depend on the particular choice of the precautionary premium. For example, although less intuitive, it would be possible to establish the precautionary premium as the certain reduction in, say, health status that has the same effect on saving as the presence of the multidimensional risk. Contrary to the case of risk aversion, a transformation of the utility function of the form $V(X)=g(v(X))$, with, say, $g^{\prime \prime}<0$ and $g^{\prime \prime \prime}>0$ does not imply in general that the precautionary premium is larger under $V$ than under $v .^{9}$ Therefore, Kihlstrom and Mirman's (1974) approach seems to be less valid for comparing higher order risk attitudes like prudence.

\subsection{Decreasing, constant, and increasing prudence in the $j^{\text {th }}$ attribute}

Pratt (1964) established the intuitive fact that decreasing absolute risk aversion implies that the risk premium is decreasing in wealth. Kimball (1990b) mapped this result to the case of precautionary saving, establishing that decreasing absolute prudence, as measured by the univariate function that he proposed, implies that the precautionary saving premium is decreasing in wealth. To extend these results to our multidimensional setting we need to specify what decreasing or increasing prudence mean, which is done in the following proposition.

Using our previous results on comparative multivariate prudence we obtain the following result

Proposition 4. The following conditions are equivalent:

1. The precautionary premium is a decreasing (resp. constant, increasing) function in attribute $j$, i.e. $\frac{\partial \Psi(X, \widetilde{e}, w)}{\partial x_{j}}<0\left(\operatorname{resp} . \frac{\partial \Psi(X, \widetilde{e}, w)}{\partial x_{j}}=0, \frac{\partial \Psi(X, \widetilde{e}, w)}{\partial x_{j}}>0\right)$.

2. The matrix $-\frac{\partial}{\partial x_{j}} P^{w}(X)$ is positive-definite (resp. null, negative-definite).

Proof The precautionary premium is a decreasing function of $x_{j}$ if and only if we have $\Psi(X, \widetilde{e}, w) \geq \Psi(X+d, \widetilde{e}, w)$ for all $d \in D_{j}$ with $D_{j}=\left\{\left(d_{0}, \cdots, d_{n}\right): d_{i}=0, i \neq j\right.$, and $\left.d_{j}>0\right\}$. Let us introduce $v_{d}$ the utility function defined by $v_{d}(x)=v(x+d)$ and let us define $w_{d}$ by $w_{d}\left(x_{0}, x_{1}, \ldots, x_{n}\right)=$ $\sum_{i=0}^{n} \rho_{i} \frac{\partial v_{d}}{\partial x_{i}}\left(x_{0}, x_{1}, \ldots, x_{n}\right)$. We clearly have $w_{d}(x)=w(x+d)$ and we check that $\Psi(X+d, \widetilde{e}, w)=\Psi\left(X, \widetilde{e}, w_{d}\right)$. We have then the following characterization. The

\footnotetext{
${ }^{9}$ This is also true in the univariate case. See e.g. Eeckhoudt and Schlesinger (1994)
} 
precautionary premium is a decreasing function of $x_{j}$ if and only if we have $\Psi(X, \widetilde{e}, w) \geq \Psi\left(X, \widetilde{e}, w_{d}\right)$ for all $d \in D_{j}$. From Proposition 3 , this is equivalent to the statement that $P^{w}(X)-P^{w_{d}}(X)$ is positive semi-definite for all $d \in D_{j}$. Remark that $P^{w_{d}}(X)=P^{w}(X+d)$ and that $P^{w}(X)-P^{w}(X+d)$ is positive semi-definite for all $d \in D_{j}$ if and only if $-\frac{\partial}{\partial x_{j}} P^{w}(X)$ is positive semi-definite.

We retrieve then the fact that the precautionary saving premium is decreasing (with respect to attribute $j$ ) if and only if our matrix measure of multivariate prudence is decreasing (with respect to attribute $j$ ) in the sense that its derivative (with respect to attribute $j$ ) is negative-definite.

Kimball (1990 a,b) makes the link between an increasing/decreasing precautionary premium and a decrease/increase of the marginal propensity to consume out of wealth in the presence of income risk. ${ }^{10}$ Let us explore how these properties pertain in our multidimensional setting. We focus on the specific case $\rho_{i}=0$, for $i=1, \ldots, n$.

The consumption function is defined by ${ }^{11}$

$$
c(X, \tilde{e})=\arg \max u\left(c, y_{1}, \ldots, y_{n}\right)+E\left[v\left(\tilde{x}_{0}+\rho_{0}\left(y_{0}-c\right), \tilde{x}_{1}, \ldots, \tilde{x}_{n}\right)\right]
$$

where $\left(y_{0}, y_{1}, \ldots, y_{n}\right)$ is kept fixed. The marginal propensity to consume out of wealth is given by $\frac{\partial c}{\partial x_{0}}$ and we want to compare $\frac{\partial c}{\partial x_{0}}(X, \tilde{e})$ with $\frac{\partial c}{\partial x_{0}}(X, 0)$; that is to say, we want to analyze the impact of the multidimensional risk $\tilde{e}$ on the marginal propensity to consume out of wealth. In the next, the inverse of $c$ (more precisely, the inverse of the function $\left.x_{0} \rightarrow c(X, \tilde{e})\right)$ is denoted by $g\left(c ; x_{1}, \ldots, x_{n}, \tilde{e}_{0}, \ldots, \tilde{e}_{n}\right)$. By definition, it satisfies

$$
g\left(c(X, \tilde{e}) ; x_{1}, \ldots, x_{n}, \tilde{e}_{0}, \ldots, \tilde{e}_{n}\right)=x_{0} .
$$

For a given function $w$ and a given $\widetilde{X}$, we also define the compensating precautionary premium $\Psi^{*}(X, \widetilde{e}, w)$ by

$$
w\left(x_{0}, \ldots, x_{n}\right)=E\left[w\left(\tilde{x}_{0}+\Psi^{*}(X, \widetilde{e}, w), \tilde{x}_{1}, \ldots, \tilde{x}_{n}\right)\right] .
$$

\footnotetext{
${ }^{10}$ As Kimball (1990 a,b) shows, understanding the effect of income risk on the slope of the consumption function is of some importance in many economic settings (e.g. in terms of taxation and asset prices). Carroll and Kimball (1996) extend Kimball's analysis by evaluating the curvature of the consumption function in the presence of income risk, i.e. the concavity of the consumption function. Carroll (2009) evaluates the response of consumption to permanent and transitory shocks.

${ }^{11}$ Notice that we are referring to consumption of the first attribute simply as consumption.
} 
The compensating precautionary premium is the additional amount of income that induces the consumer to save the same amount in the presence of the multidimensional risk $\tilde{e}$ as in the absence of it. The following proposition establishes the link between the decrease /increase in income (first attribute) of the equivalent and compensating precautionary premia and the effect of the multidimensional risk on the marginal propensity to consume.

Proposition 5. The following conditions are equivalent

1. The equivalent precautionary premium $\Psi(X, \widetilde{e}, w)$ is decreasing (resp. increasing) with respect to $x_{0}$.

2. The compensating precautionary premium $\Psi^{*}(X, \widetilde{e}, w)$ is decreasing (resp. increasing) with respect to $x_{0}$.

3. The marginal propensity to consume out of wealth is higher (resp. lower) in the presence of the multidimensional risk $\tilde{e}$.

Proof See Appendix.

Linking Proposition 5 with Proposition 4 we obtain that a necessary and sufficient condition for the marginal propensity to consume out of wealth to be higher in the presence of the multidimensional risk $\tilde{e}$ is that the matrix measure of multivariate prudence is decreasing in wealth, in the sense that $-\frac{\partial}{\partial x_{0}} P^{w}(X)$ is positivedefinite. Importantly, this condition implies that the decrease of the usual measure of prudence, $\frac{-v_{000}}{v_{00}}$, is generally not sufficient to establish whether the marginal propensity to consume is higher or lower in the presence of a risk that is multidimensional. Instead, a necessary and sufficient condition requires information about preferences towards all the attributes that enter the utility function.

\subsection{The Drèze-Modigliani substitution effect revisited}

Drèze and Modigliani (1972) and later Kimball (1990b) showed that decreasing absolute risk aversion implies that the precautionary saving motive is stronger than risk aversion, in the sense that the precautionary saving premium is larger than the risk premium. Drèze and Modigliani (1972) called the incentive to save beyond what one would expect from the decrease in utility caused by uncertainty, the substitution effect. In the next, we first show that this result pertains when the absolute risk aversion is assumed to be decreasing in wealth (i.e. in $x_{0}$ ) and 
when current saving can only be transformed into higher future income, so $\rho_{i}=0$ for $i=1,2, . ., n$.

As Karni (1979) does, we define the risk premium, $\Pi(X, \widetilde{e}, v)$, as the certain reduction of income (first attribute) that has the same effect on utility as the introduction of a multidimensional risk $\widetilde{e}$ :

$$
E[v(\widetilde{X})]=v\left(x_{0}-\Pi(X, \widetilde{e}, v), x_{1}, \ldots, x_{n}\right) .
$$

Differentiating this expression with respect to $x_{0}$ we obtain

$$
E\left[v_{0}(\widetilde{X})\right]=\left(1-\frac{\partial \Pi(X, \widetilde{e}, v)}{\partial x_{0}}\right) v_{0}\left(x_{0}-\Pi(X, \widetilde{e}, v), x_{1}, \ldots, x_{n}\right) .
$$

Therefore, the risk premium is decreasing in $x_{0}$ if and only if we have

$$
E\left[v_{0}(\widetilde{X})\right]>v_{0}\left(x_{0}-\Pi(X, \widetilde{e}, v), x_{1}, \ldots, x_{n}\right) .
$$

By definition, this inequality becomes an equality when replacing the risk premium $\Pi(X, \widetilde{e}, v)$ by the equivalent precautionary premium $\Psi\left(X, \widetilde{e}, v_{0}\right)$. Given the concavity of $v$ in $x_{0}$, this has the following corollary.

Proposition 6. When $\rho_{i}=0, i=1, \ldots, n$, the following conditions are equivalent

1. The risk premium, as defined in Eq.(2.7), is decreasing with respect to $x_{0}$.

2. The precautionary premium, as defined in Eq.(2.2) with $\rho_{i}=0$ for $i=$ $1,2, . ., n$, is larger than the risk premium.

3. The matrix $J \equiv P-A$, with $P \equiv\left[\frac{-v_{0 i j}}{v_{00}}\right](X)$ and $A \equiv\left[\frac{-v_{i j}}{v_{0}}\right](X)$, is positive semi-definite.

Proof The equivalence of (1) and (2) follows from the discussion above. To show the equivalence of (3) and (1) notice that the matrix $P=\left[\frac{-v_{0 i j}}{v_{00}}\right]$ can be written as $P=A+\left[\frac{\partial}{\partial x_{0}} A\right] \frac{v_{0}}{v_{00}}$. Therefore, $[P-A]=\left[\frac{\partial}{\partial x_{0}} A\right] \frac{v_{0}}{v_{00}}$. Given $v_{00}<0,[P-A]$ is positive definite if, and only if, $\left[\frac{-\partial}{\partial x_{0}} A\right]$ is positive definite. But, according to Karni (1979), this is true if and only if the risk premium is decreasing in $x_{0}$.

Of course, if the risk premium is an increasing (resp. constant) function of income, then the precautionary premium is smaller than (resp. equal to) the risk premium. In this way, the important Drèze-Modigliani substitution effect, which 
says that the precautionary saving motive is at least as strong as risk aversion (given decreasing risk aversion) extends naturally to the multivariate case.

We now consider a more general case. We do not assume anymore that $\rho_{i}=0$ for $i \neq 0$. For a given $\widetilde{X}$, we may measure the impact of a shift in the direction of $\left(\rho_{0}, \rho_{1}, \ldots, \rho_{n}\right)$ by introducing the function $\Pi^{\rho}$ defined by $\Pi^{\rho}(X, \widetilde{e}, v, s)=\Pi(\widetilde{X}+s \rho)$. We will say that the risk premium is decreasing in the direction of $\rho$ if $s \rightarrow$ $\Pi(\widetilde{X}+s \rho)$ is decreasing or, equivalently, if $\frac{\partial}{\partial s} \Pi^{\rho}(X, \widetilde{e}, v, s)<0$. This concept corresponds to the concept of endogenously decreasing risk aversion as in Drèze and Modigliani (1972) and characterizes the situations where the risk aversion decreases with the optimal level of saving (that is endogenously determined).

We have

$$
E[v(\widetilde{X}+s \rho)]=v\left(x_{0}+\rho_{0} s-\Pi^{\rho}(X, \widetilde{e}, v, s), x_{1}+\rho_{1} s, \ldots, x_{n}+\rho_{n} s\right) .
$$

Differentiating this expression with respect to $s$ we obtain at $s=0$,

$$
\begin{aligned}
E[w(\widetilde{X})]= & w\left(x_{0}-\Pi^{\rho}(X, \widetilde{e}, v, 0), x_{1}, \ldots, x_{n}\right) \\
& -\frac{\partial \Pi^{\rho}(X, \widetilde{e}, v, 0)}{\partial s} v_{0}\left(x_{0}-\Pi^{\rho}(X, \widetilde{e}, v, 0), x_{1}, \ldots, x_{n}\right) \\
= & w\left(x_{0}-\Pi(X, \widetilde{e}, v), x_{1}, \ldots, x_{n}\right) \\
& -\frac{\partial \Pi^{\rho}(X, \widetilde{e}, v, 0)}{\partial s} v_{0}\left(x_{0}-\Pi(X, \widetilde{e}, v), x_{1}, \ldots, x_{n}\right) .
\end{aligned}
$$

The risk premium is decreasing in the direction of $\rho$ if and only if we have

$$
E[w(\widetilde{X})]>w\left(x_{0}-\Pi(X, \widetilde{e}, v), x_{1}, \ldots, x_{n}\right) .
$$

By definition, this inequality becomes an equality when replacing $\Pi(X, \widetilde{e}, v)$ by the equivalent precautionary premium $\Psi(X, \widetilde{e}, w)$. Given the concavity of $v$ in $x_{0}$, this has the following corollary

Proposition 7. For general $\rho$, the following conditions are equivalent

1. The risk premium is decreasing in the direction of $\rho$.

2. The precautionary premium is larger than the risk premium.

3. The matrix $J \equiv P^{v}-A^{v}$, with $P^{v} \equiv\left[\frac{-v_{0 i j}}{v_{00}}\right](X)$ and $A^{v} \equiv\left[\frac{-v_{i j}}{v_{0}}\right](X)$, is positive definite. 
Proof The equivalence of (1) and (2) follows from the discussion above. To show the equivalence of (3) and (1) notice that the matrix $P^{v}=\left[\frac{-v_{0 i j}}{v_{00}}\right]$ can be written as $P^{v}=A^{v}+\left[\frac{\partial}{\partial s} A^{v, \rho}(0)\right] \frac{v_{0}}{w_{0}}$ where $A^{v, \rho}(s) \equiv A(X+s \rho)$. Note that $A^{v, \rho}=A^{v^{\rho, s}}$ where $v^{\rho, s}(X) \equiv v(X+s \rho)$. Therefore, $\left[P^{v}-A^{v}\right]=\left[\frac{\partial}{\partial s} A^{v, \rho}(0)\right] \frac{v_{0}}{w_{0}}$. Given $w_{0}<0,\left[P^{v}-A^{v}\right]$ is positive definite if, and only if, $\left[\frac{\partial}{\partial s} A^{\rho, v}(0)\right]$ is positive definite or equivalently if and only if $A^{v^{\rho, s}}-A^{v}$ is negative definite for all $s>0$. Following Karni (1979) this means that $v^{\rho, s}$ is less risk averse than $v$ or equivalently that $\Pi\left(X, \widetilde{e}, v^{\rho, s}\right)<$ $\Pi(X, \widetilde{e}, v)$. It suffices to remark that $\Pi\left(X, \widetilde{e}, v^{\rho, s}\right)=\Pi((X+s \rho), \widetilde{e}, v)$ to see that the condition $\Pi\left(X, \widetilde{e}, v^{\rho, s}\right)<\Pi(X, \widetilde{e}, v)$ for all $s>0$ is equivalent to the decrease of $\Pi(X, \widetilde{e}, v)$ in the direction of $\rho$.

\subsection{Examples}

To illustrate some of the results obtained so far we will consider two specific examples. In the first example we introduce relative price variability in an otherwise standard model of precautionary saving. In the second example we consider a simple model, in the spirit of Duesenberry (1949) and Gali (1994), where consumers derive satisfaction from their own income/consumption and also from their relative position in society.

\subsubsection{Income and relative price uncertainty}

Imagine a world with two tradable goods. Suppose that in each of two dates the consumer selects how much to purchase of each good and in the first period the consumer also selects how much to save $s$ out of his or her total income $x$. Let $y_{i}$ and $z_{i}, i=0,1$, be the amount consumed of the goods at date $i$, and let $q_{i}$ be the relative price of good $z$ at date $i$. Then, the budget constraint for date 0 is $y_{0}+q_{0} z_{0}=x_{0}-s$ and the corresponding constraint for date 1 is $y_{1}+q_{1} z_{1}=x_{1}+s$. We assume that there is uncertainty over the date 1 income and the date 1 relative price. In particular, we assume $\widetilde{x}_{1}=x_{0}+\widetilde{e}_{x}$ and $\widetilde{q}_{1}=q_{0}+\widetilde{e}_{p}$, where $\widetilde{e}_{x}$ and $\widetilde{e}_{q}$ are mean-zero random variables with a variance-covariance matrix $V^{e} \equiv\left[\sigma_{i j}\right]$ with $\sigma_{i j}=\operatorname{cov}\left(\widetilde{e}_{x}, \widetilde{e}_{q}\right)$. We also assume that the date 1 allocation is done after the realization of the random shocks. Finally, we assume that the period utility has a power/Cobb-Douglas form: $u\left(y_{i}, z_{i}\right)=\frac{\left(y_{i}^{\alpha} z_{i}^{\beta}\right)^{1-\gamma}}{1-\gamma}$, with $\alpha+\beta=1{ }^{12}$

\footnotetext{
${ }^{12}$ The case of labor income uncertainty with endogenous labor supply is a sub-case of this example in which $q=x$ is the wage rate, $z$ is leisure demand, and $y$ consumption (See Floden,
} 
To evaluate the effect of the multidimensional risk on saving behavior we can proceed in two steps:

1) Choose $y_{i}$ and $z_{i}$ to maximize utility at each date, the level $s$ of saving being given. This yields the lifetime indirect utility function

$$
H(s)=K\left\{\left[q_{0}^{\beta}\left(x_{0}-s\right)\right]^{1-\gamma}+E\left[q_{1}^{\beta}\left(x_{1}+s\right)\right]^{1-\gamma}\right\},
$$

where $K$ is a constant.

2) Select savings to maximize the indirect utility function. The first order condition for this problem is

$$
q_{0}^{\beta(1-\gamma)}\left(x_{0}-s\right)^{-\gamma}=E q_{1}^{\beta(1-\gamma)}\left(x_{1}+s\right)^{-\gamma} .
$$

Clearly, this is an example of our more general model. We readily retrieve that the local compensating precautionary premium equals $\Psi=\frac{1}{2} \operatorname{tr}\left[V^{e} P\right]$, where the matrix measure of multivariate prudence $P$ is given by

$$
P=\left[\begin{array}{cc}
(1+\gamma) x_{0}^{-1} & \beta(1-\gamma) q_{0}^{-1} \\
\beta(1-\gamma) q_{0}^{-1} & \beta(1-\gamma)[1+\beta(1-\gamma)] \gamma^{-1} x_{0} q_{0}^{-2}
\end{array}\right]
$$

The first element of $P,(1+\gamma) x_{0}^{-1}$, is the measure of prudence that would arise if income were the only source of risk. Introducing relative price uncertainty in an otherwise standard model of precautionary saving has a number of important implications. First, an increase in risk aversion, in the sense that the parameter $\gamma$ is higher, does not in general imply a stronger precautionary saving motive (i.e. $P^{\gamma_{A}}-P^{\gamma_{B}}$, with $\gamma_{A}>\gamma_{B}$ is not positive semi-definite). ${ }^{13}$ Second, a positive third derivative of the utility function with respect to income is not sufficient for a positive precautionary saving motive. Instead, a sufficient condition for $P$ to be positive semi-definite for all $x$ and $q$, and as a result for multivariate prudence to occur, is $\gamma \leq 1$. Third, the risk premium is decreasing in the level of income and the precautionary premium is larger than the risk premium if $\gamma \geq \frac{1+\beta}{\beta}$. Fourth, the precautionary premium is decreasing in income, and so the marginal propensity to consume is higher in the presence of the multidimensional risk, if $1 \leq \gamma \leq \frac{1+\beta}{\beta}$.

2006, and Nocetti and Smith, 2011).

${ }^{13}$ This is consistent with Floden (2006) and Nocetti and Smith (2011), who show that an increase in risk aversion has an ambiguous effect on the strength of precautionary saving in a model with wage uncertainty, endogenous labor supply, and power/Cobb-Douglas preferences. It is simple to show that if the income and the relative price are uncorrelated a sufficient condition for an increase in risk aversion to increase the precautionary saving premium is $\gamma \geq \frac{1+\beta}{\beta}$. 
In particular, if $\gamma<1$ the precautionary premium will be positive, but it may be lower than the risk premium and the marginal propensity to consume may also be lower. If $1<\gamma<\frac{1+\beta}{\beta}$ the marginal propensity to consume will be higher in the presence of the risk, but the precautionary premium may be negative and lower than the risk premium. Finally, if $\gamma>\frac{1+\beta}{\beta}$ the precautionary premium will be higher than the risk premium, but it may be negative and the multidimensional risk may reduce the marginal propensity to consume. This contrasts sharply with the standard univariate model in which, given isoelastic preferences, the precautionary premium is positive, it increases with risk aversion, it is larger than the risk premium, and is decreasing in income (so it implies a higher propensity to consume in the presence of income risk).

\subsubsection{Keeping up with the Joneses}

Let $c_{0}=x_{0}-s$ and $c_{1}=x_{1}+s$ denote first and second period consumption and $y_{i}$ the average level of consumption in society at date $i$. We assume that each consumer's level of consumption is small relative to that of society, so the selection of a different level of saving for a given consumer does not affect $y_{i}$. Suppose that $\widetilde{x}_{1}=x_{0}+\widetilde{e}_{x}$ and $\widetilde{y}_{1}=y_{0}+\widetilde{e}_{y}$, where $\widetilde{e}_{x}$ and $\widetilde{e}_{y}$ are mean-zero random variables with a variance-covariance matrix $V^{e} \equiv\left[\sigma_{i j}\right]$ with $\sigma_{i j}=\operatorname{cov}\left(e_{x}, e_{y}\right)$, and that the consumer's lifetime preferences are given by $H(s)=u\left(c_{0}, c_{0}-y_{0}\right)+$ $E u\left(\widetilde{c}_{1}, \widetilde{c}_{1}-\widetilde{y}_{1}\right)$, with $u\left(c_{i}, c_{i}-y_{i}\right)=-e^{-\alpha c_{i}-\beta\left(c_{i}-y_{i}\right)}(\alpha+\beta)^{-1}$.

The first order condition associated with optimal saving is $e^{-\alpha c_{1}-\beta\left(c_{1}-y_{1}\right)}=$ $E e^{-\alpha c_{2}-\beta\left(c_{2}-y_{2}\right)}$. From this we can easily derive the local precautionary premium $\Psi=\frac{1}{2} \operatorname{tr}\left[V^{e} P\right]$, where the matrix measure of multivariate prudence $P^{w}$ is given by

$$
P^{w}=\left[\begin{array}{cc}
\alpha+\beta & \beta(\alpha+\beta) \\
\beta(\alpha+\beta) & \frac{\beta^{2}}{\alpha+\beta}
\end{array}\right] .
$$

We point out that if $e_{x}$ and $e_{y}$ are jointly normally distributed the approximation is exact and, as a result, the measure of multivariate prudence captures exactly the strength of the precautionary saving motive (i.e. $s=\frac{1}{4} \operatorname{tr}\left[V^{e} P^{w}\right]$ ). Furthermore, the matrix measure of risk aversion is independent of $x$ and $y$ (i.e. multivariate risk aversion is constant). Consistent with Proposition 6, this implies that the risk premium equals the precautionary premium and that the matrix measures of risk aversion and of prudence are identical (also implied by Proposition 3). Since the measure of prudence is constant, the marginal propensity to consume is not affected by the presence of the multidimensional risk (Proposition 5). 


\section{Multivariate Downside Risk Aversion}

\subsection{Precautionary saving as endogenous harm disaggregation}

In the context of a single-attribute utility function, precautionary saving has been linked with a preference towards disaggregation of harms known as downside risk aversion (Menezes et al 1980). In its presentation by Eeckhoudt and Schlesinger (2006) downside risk aversion is defined as follows: Given a certain reduction in wealth $-k$ and a mean-zero random variable $\widetilde{e}$, an individual is downside risk averse if he prefers the lottery $[x-k ; x+\widetilde{e}]$ to the lottery $[x ; x-k+\widetilde{e}]$, where the outcomes occur with equal probability. Intuitively, an individual is downside risk averse if he prefers to locate an additional harm in the form of a mean-zero risk $\widetilde{e}$ to states of nature in which wealth is high. Equivalently, he prefers a reduction in wealth $-k$ in states in which the risk is not present. In other words, the individual perceives the harms $\widetilde{e}$ and $-k$ as 'mutually aggravating' (Kimball, 1993). In an expected utility framework this is equivalent to a positive third derivative of the utility function, so downside risk aversion is also equivalent to a positive precautionary saving motive. This should not be too surprising: in the context of a consumption/saving problem an individual that displays downside risk aversion (or equivalently, prudence) selects to mitigate the future risk by transferring resources from the period in which the risk is not present.

To extend this idea to a multidimensional framework we propose the following definition.

Definition 3. An individual displays Multivariate Downside Risk Aversion (MDRA) if for all $k \in \mathbb{R}_{+}^{*}$,

$$
[X-k \rho ; \tilde{X}] \succ[X ; \widetilde{X}-k \rho]
$$

where, in each lottery, the outcomes have equal probability.

Again, the intuition of this definition is that a consumer prefers to locate a harm in the form of a multidimensional risk to states of nature in which the value of the attributes are relatively high. Equivalently, he would rather have a lower value of the attributes when the multidimensional risk is not present. In the expected utility framework, an agent displays MDRA if the following condition holds

$$
\frac{1}{2} u(X-k \rho)+\frac{1}{2} E[u(\widetilde{X})]>\frac{1}{2} u(X)+\frac{1}{2} E[u(\widetilde{X}-k \rho)] .
$$

The following proposition establishes the condition for preferences to display MDRA. 
Proposition 1. An Individual displays MDRA if and only if the function $w(X)=$ $\sum_{i=0}^{n} \rho_{i} \frac{\partial u}{\partial x_{i}}(X)$ is convex in $X$.

Proof MDRA $\Rightarrow w$ convex: we have $E[u(\tilde{X})]-E\left[u\left(\tilde{x}_{0}-\rho_{0} k, \tilde{x}_{1}-\rho_{1} k, \ldots, \tilde{x}_{n}-\rho_{n} k\right)\right]>$ $u(X)-u(x-k \rho)$. Since $k$ can be made arbitrarily small, we get $E[w(\tilde{X})]>$ $w(X)$. By Jensen's inequality, this implies that $w$ is convex.

$w$ convex $\Rightarrow$ MDRA: By Jensen's inequality, we have $E[w(\tilde{X})]>w(X)$ for all random variable $\widetilde{X}$. This implies that for all $h>0$,

$$
E[w(\widetilde{X}-h \rho)]>w(X-\rho)
$$

hence for all $k>0$,

$$
\int_{0}^{k} E[w(\widetilde{X}-h \rho)] d h>\int_{0}^{k} w(\widetilde{X}-h \rho) d h .
$$

We then get

$$
E[u(\widetilde{X})]-E[u(\widetilde{X}-k \rho)]>u(X)-u(X-k \rho),
$$

which implies that the individual displays MDRA.

Now recall that convexity of $w$ in $X$ is also necessary and sufficiency for multivariate prudence. Therefore, our definition of MDRA is equivalent to a positive precautionary saving motive. An individual that displays MDRA (or equivalently, multivariate prudence) selects to decrease the current level of consumption and increase the future level of the attributes in order to mitigate the pain caused by the multidimensional risk.

\subsection{The intensity of MDRA}

Despite the equivalency of the condition under which an individual displays multivariate prudence and MDRA their intensity need not be measured in the same way. The reason is that the intensity of prudence is properly captured by the magnitude of the compensation that has the same effect on an optimally selected decision variable as the presence of a risk. Therefore, such compensation equalizes the expected marginal utility of the decision variable (saving) in the presence and absence of the risk. Instead, just as in the case of risk aversion, the intensity 
of downside risk aversion is better captured by the compensation that makes a person indifferent in terms of expected utility in the presence and absence of a risk. This has been emphasized in the univariate framework by a number of authors (e.g. Modica and Scarsini (2005), Jindapon and Neilson (2007), Crainich and Eeckhoudt (2008), Keenan and Snow (2009), Denuit and Eeckhoudt (2010)).

To evaluate the intensity of MDRA we consider, as Crainich and Eeckhoudt (2008) do in a univariate framework, the certain amount of income $\theta(X, \widetilde{e}, u)$ that compensates for the difference in expected utility, i.e., such that

$$
\frac{1}{2} u(X-k \rho)+\frac{1}{2} E[u(\tilde{X})]=\frac{1}{2} u(X+\theta \delta)+\frac{1}{2} E[u(\tilde{X}-k \rho)] .
$$

Let $A$ (resp. $B$ ) denote the left (right) hand side of the equality in Eq. (3.1). A second order approximation yields

$$
\begin{aligned}
& A \approx u(X-k \rho)+u(X)+\frac{1}{2} \sum_{i=0}^{n} \sum_{j=0}^{n} u_{i j}(X) \sigma_{i j} \\
& B \approx u(X+\theta \delta)+u(X-k \rho)+\frac{1}{2} \sum_{i=0}^{n} \sum_{j=0}^{n} u_{i j}(X-k \rho) \sigma_{i j}
\end{aligned}
$$

hence

$$
u(X)+\frac{1}{2} \sum_{i=0}^{n} \sum_{j=0}^{n} u_{i j}(X) \sigma_{i j} \approx u(X+\theta \delta)+\frac{1}{2} \sum_{i=0}^{n} \sum_{j=0}^{n} u_{i j}(X-k \rho) \sigma_{i j} .
$$

Using a first order approximation for small $k$ and small $\theta$, we get $\theta u_{0}(X)-$ $\frac{k}{2} \sum_{i=0}^{n} \sum_{j=0}^{n} w_{i j}(X) \sigma_{i j} \approx 0$, and

$$
\theta(X, \widetilde{e}, u) \approx \frac{k}{2} \sum_{i=0}^{n} \sum_{j=0}^{n} \frac{w_{i j}(X)}{u_{0}(X)} \sigma_{i j}
$$

Letting $D^{u}$ denote the matrix $D^{u} \equiv\left[\frac{w_{i j}}{u_{0}}\right]$, we have $D^{u}=\left(-\frac{w_{0}}{u_{0}}\right) P^{w}$ and

$$
\theta(X, \widetilde{e}, u) \approx \frac{k}{2} \operatorname{tr}\left[V^{e} D^{u}\left(x_{0}, \ldots, x_{n}\right)\right] .
$$

$D^{u}$ is our proposed matrix measure of local MDRA. The following proposition, which extends Proposition 1, establishes a global property of $D^{u}$ relative to $\theta$. 
Proposition 2. The following conditions are equivalent.

1. An individual with expected utility and utility function $u$ displays MDRA.

2. The function $w$ is convex in $X$.

3. The compensating amount is nonnegative, $\theta(X, \widetilde{e}, u) \geq 0, \forall X$.

4. The matrix $D^{u}$ is positive semi-definite.

Proof We showed that $(1) \Leftrightarrow(2)$ in Proposition 1

(1) $\Leftrightarrow$ (3) Immediate since $u$ is nondecreasing.

(2) $\Leftrightarrow(4)$ The function $w$ is convex if and only if the matrix $\left[w_{i j}\right]$ is positive semi-definite. Since $u_{0}>0$, this is equivalent to $D^{u}$ positive semi-definite.

Therefore, the compensating amount $\theta$ is non-negative whenever the precautionary premium is and the matrix measure of MDRA is positive semi-definite whenever the measure of multivariate prudence is. A natural question that arises then is: can we compare the MDRA attitude of two agents as we did with the measure of multivariate prudence? To answer this question we begin with the following definition.

Definition 4. Agent A, with utility function $u_{A}$, is said more multivariate downside risk averse than $A$ gent $B$, with utility function $u_{B}$, if $\theta\left(X, \widetilde{e}, u_{A}\right) \geq \theta\left(X, \widetilde{e}, u_{B}\right)$, $\forall \tilde{X}$.

We obtain the following local result,

Proposition 3. In the case of small risks, $\theta\left(X, \widetilde{e}, u_{A}\right) \geq \theta\left(X, \widetilde{e}, u_{B}\right)$ if and only if the matrix $\left[D^{u_{A}}-D^{u_{B}}\right]\left(x_{0}, x_{1}, \ldots, x_{n}\right)$ is positive semi-definite.

Proof The proof follows the same lines as the proof of Proposition 2, using the fact that $\theta_{A}-\theta_{B} \approx \frac{k}{2} \operatorname{tr}\left[V^{e}\left(D^{u_{A}}-D^{u_{B}}\right)(X)\right]$.

Unfortunately, we have not been able to establish a global condition linking $\theta\left(X, \widetilde{e}, u_{A}\right)$ and $\theta\left(X, \widetilde{e}, u_{B}\right)$ with the matrix $\left[D^{u_{A}}-D^{u_{B}}\right](X)$ for all risks. This, however, should not be very surprising given the difficulty in finding global conditions even in the univariate case (e.g. Keenan and Snow 2009). 


\subsection{Two applications}

In this section we first present a simple model of social discounting which permits to establish a closer connection between the proposed measures of MDRA and of multivariate prudence. Then, we study a complementary problem to that of precautionary saving presented above; namely, the problem of optimal saving when the rates of return are uncertain. We show that whether such uncertainty generates extra saving depends on the intensity of MDRA relative to the intensity of multivariate risk aversion.

\subsubsection{Social discounting with multiple goods}

Suppose that there are two dates and that the welfare of the representative consumer is characterized by a discounted intertemporal expected utility function $H\left(X_{0}, \widetilde{X}_{1}\right)=u\left(X_{0}\right)+E\left[e^{-\lambda} v\left(\widetilde{X}_{1}\right)\right]$, where $\lambda$ captures the pure rate of time preference. ${ }^{14}$ Following Gollier (2010), one can define $n$ social discount rates, one for each good. We will focus on good 0, which, as before, represents the income. To define the social discount rate imagine a marginal project that decreases current income by a sure (small) amount $\varepsilon$ and increases income at date 1 by $\varepsilon e^{r}$. Implementing this project would increase social welfare if the net trade-off is positive. This rule can be written as $r \geq \hat{r}=\lambda+\ln \left(E v_{0}\left(\widetilde{X}_{1}\right) / u_{0}\left(X_{0}\right)\right)$, where $\hat{r}$ is the minimum threshold that the project must exceed to be socially efficient. This threshold corresponds to the discount rate at which each project should be discounted in order to evaluate its social efficiency. It is called social discount rate (for good 0). For expositional clarity we will focus on the case $v=u$ and $X_{1}=X_{0}=X$.

We can now ask two related questions. First, what is the additional amount of date 1 income that would make the social discount rate equal to that in an economy without uncertainty (i.e. such that $\hat{r}=\lambda)$ ? That is, given $\rho_{0}=1$ and $\rho_{i}=0$ for $i=1,2, . ., n$, what is the additional amount $\kappa$ such that $E u_{0}(\tilde{X}+\kappa \delta)=u_{0}(X)$. Clearly, such additional amount equals the compensating precautionary premium defined in Section 3, i.e. $\kappa=\Psi^{*}\left(X, \widetilde{e}, u_{0}\right)$. As we have seen above, for small risks we have $\Psi^{*}\left(X, \widetilde{e}, u_{0}\right) \approx \frac{1}{2} \operatorname{tr}\left[V^{e} P^{u_{0}}(X)\right]$. More directly we can ask: what is the

\footnotetext{
${ }^{14}$ Our analysis is closely related to that of Gollier (2010), who evaluated the problem of social discounting in a framework where the representative consumer has a utility function defined over two attributes, income/consumption and environmental quality, which evolve stochastically over time.
} 
reduction in the social discount rate, say $\Delta \hat{r}$, that arises due to the existence of the multidimensional risk? For small risks the answer is $\Delta \hat{r} \approx-\frac{u_{00}}{u_{0}} \frac{1}{2} \operatorname{tr}\left[V^{e} P^{u_{0}}(X)\right]=$ $\frac{1}{2} \operatorname{tr}\left[V^{e} D^{u}(X)\right]=\theta(X, \widetilde{e}, u)$.

In other words, in order to remain indifferent in terms of the multidimensional risk, the representative consumer requires an additional amount of income $\Psi^{*}\left(X, \widetilde{e}, u_{0}\right)$ or an additional rate of return $\theta(X, \widetilde{e}, u)^{15}$. The matrix measures $P^{u_{0}}$ and $D^{u}$ capture, respectively, the magnitude of such additional compensations.

More generally, let us now consider general $\rho_{i}$ s and let us consider a marginal project that decreases current income by a sure small amount $\varepsilon$ and increases future consumption by $\varepsilon e^{r} \rho$. The minimum threshold that the rate of return $r$ must exceed for the project to be socially efficient is then given by $\hat{r}=\lambda+$ $\ln \left(E w\left(\widetilde{X}_{1}\right) / u_{0}\left(X_{0}\right)\right)$. The additional amount $\kappa$ of date 1 income that would make the social discount rate equal to that in an economy without uncertainty (i.e. where $\widetilde{X}_{1}$ is replaced by $\left.X_{1}\right)$ is then such that $E w\left(\widetilde{X}_{1}+\kappa \delta\right)=w\left(X_{1}\right)$ and $\kappa$ again corresponds to the compensating precautionary premium, i.e. $\kappa=\Psi^{*}(X, \widetilde{e}, w)$.

\subsubsection{Saving with risky multi-dimensional rate of return}

In our analysis of Section 2, we considered a deterministic rate of return on income and on the other attributes. It is likely, however, that consumers face uncertainty surrounding the rate of return (e.g. the quality of health care may be uncertain). In the context of a single source of risk on the rate of return, this problem has been analyzed by Sandmo (1970), Rothschild and Stiglitz (1971), and more recently Eeckhoudt and Schlesinger (2008). In this context, rate of return risk induces extra saving if the index of prudence $\frac{-v^{\prime \prime \prime}(x+y) x}{v^{\prime \prime}(x+y)}$ is larger than 2 where $y$ is the future labor income ${ }^{16}$. Equivalently, the condition can be written as $d \geq 2 a$, where $d \equiv \frac{v^{\prime \prime \prime}(x+y) x}{v^{\prime}(x+y)}$ is an index of downside risk aversion and $a \equiv-\frac{v^{\prime \prime}(x+y) x}{v^{\prime}(x+y)}$ is an index of risk aversion. Our objective is to generalize this analysis to the case of multidimensional uncertainty over the rate of return.

Let us then analyze the following problem where the agent determines an

\footnotetext{
${ }^{15}$ Alternatively, the social discount rate in a society with a pure rate of time preference equal to $\hat{\lambda}=\lambda+\theta$ and facing the multidimensional risk is the same (at least for small risks) as that in a society with a pure rate of time preference $\lambda$ and no risk.

${ }^{16}$ When future labor income is zero we can set $y=0$ and the index corresponds to Kimball's measure of relative prudence.
} 
optimal saving level $s$ in the presence of an uncertain return rate $\tilde{\rho}$,

$$
\arg \max _{s} H(s) .
$$

with

$$
H(s)=u\left(X_{0}-s \delta\right)+E\left[v\left(X_{1}+s \tilde{\rho}\right)\right] .
$$

The solution is denoted by $\widehat{s}$ and characterized by $H^{\prime}(\widehat{s})=0$.

Our objective is to compare $\widehat{s}$ with $s^{*}>0$, the amount of savings under certainty (which we assume to be positive). Such comparison is given in the following proposition, which also relates the condition for extra saving in the presence of multidimensional rate of return risk to the matrix measures of MDRA and of risk aversion.

Proposition 4. The following conditions are equivalent:

1. $\widehat{s} \geq s^{*}$

2. The function $W(\rho)=\sum_{i=0}^{n} \rho_{i} \frac{\partial v}{\partial x_{i}}\left(X_{1}+s \rho\right)$ is convex in $\rho$.

3. The matrix $Z=s D^{v}-2 A$ is positive definite, where $D^{v} \equiv\left[\frac{w_{i j}}{v_{0}}\right]$ is the matrix measure of downside risk aversion and $A \equiv\left[-\frac{v_{i j}}{v_{0}}\right]$ is Karni's matrix measure of risk aversion.

Proof We have $u\left(X_{0}-\widehat{s} \delta\right)=E\left[v\left(X_{1}+\widehat{s} \tilde{\rho}\right)\right]$ and $u\left(X_{0}-s^{*} \delta\right)=E\left[v\left(X_{1}+s^{*} \tilde{\rho}\right)\right]$. Since $H^{\prime}(s)$ is decreasing, the condition $\widehat{s} \geq s^{*}$ is equivalent to $H^{\prime}\left(s^{*}\right) \geq 0$ or to $E\left[w\left(X_{1}+s^{*} \tilde{\rho}\right)\right] \geq E\left[w\left(X_{1}+s^{*} \rho\right)\right]$. Since we want this condition to be satisfied for all $\tilde{\rho}$ and all $X_{0}$, this condition is then equivalent to the convexity of $W$ with respect to $\rho$. The second order conditions of convexity give 3 .

In other words, uncertainty over the multidimensional rate of return generates extra saving if the strength of downside risk aversion, as measured by the matrixmeasure $D^{v}$, is sufficiently large relative to the strength of risk aversion, measured by the matrix measure $A$, in the sense that the difference $s D^{v}-2 A$ is positive definite. In the appendix we show that this additional saving can also be motivated as a more basic preference towards harm disaggregation in lotteries where the harms enter multiplicatively. 


\section{Conclusion}

The theory of precautionary saving and the measurement of the strength of the precautionary saving motive have been topics of extensive research. In a review of the literature Carroll and Kimball (2008) conclude that "The qualitative and quantitative aspects of the theory of precautionary behavior are now well established." Although this is certainly the case in the context of a single attribute utility function and a single source of risk much less is known about precautionary behavior in the presence of a multidimensional risk. The objective of this paper has been to start filling this gap in the literature. We derived a matrix measure of multivariate prudence and we showed that, in the presence of a multidimensional risk, this measure is useful for comparing precautionary behavior among individuals and for comparing the strength of precautionary saving relative to the strength of risk aversion (i.e. the Drèze-Modigliani (1972) substitution effect). Furthermore, this measure also allowed us to characterize the concepts of increasing and decreasing prudence and the effect of uncertainty on the marginal propensity to consume out of wealth in a multivariate setting.

Extending the work of Eeckhoudt and Schlesinger (2006) and Eeckhoudt et al (2007), we also showed that precautionary saving behavior in the presence of a multidimensional risk is closely related with a preference towards lotteries in which a multidimensional risk is present when the level of the attributes is low rather than when the level of the attributes is high. We proposed an alternative measure that captures the strength of such preference and showed that this alternative measure is useful for evaluating a number of economic problems.

Two interesting and related topics for future research are 1) the analysis of higher order preferences towards multidimensional risks and the strength of such

preferences and 2) the evaluation of behavior towards multidimensional risks in the presence of other background multidimensional risks.

\section{Appendix}

\subsection{Proof of Proposition 3}

$(1) \Leftrightarrow(2)$ : By definition of $\Psi(X, \widetilde{e}, w)$ and $w^{-1}$, we have

$$
x_{0}-\Psi(X, \widetilde{e}, w)=w^{-1}\left(E[w(\tilde{X})], x_{1}, \ldots, x_{n}\right),
$$


hence $\Psi(X, \widetilde{e}, w)=x_{0}-w^{-1}\left(E[w(\widetilde{X})], x_{1}, \ldots, x_{n}\right)$. The condition $\Psi\left(X, \widetilde{e}, w_{A}\right) \geq$ $\Psi\left(X, \widetilde{e}, w_{B}\right)$ is then equivalent to

$$
w_{A}^{-1}\left(E\left[w_{A}(\tilde{X})\right], x_{1}, \ldots, x_{n}\right) \leq w_{B}^{-1}\left(E\left[w_{B}(\tilde{X})\right], x_{1}, \ldots, x_{n}\right) .
$$

By composing both sides of Equation (5.1) by the function $w_{A}\left(\cdot, x_{1}, \ldots, x_{n}\right)$, which is nonincreasing, we have

$$
\varphi\left(E\left[w_{B}(\tilde{X})\right], x_{1}, \ldots, x_{n}\right) \leq E\left[w_{A}(\tilde{X})\right] .
$$

We have $w_{A}(\tilde{X})=\varphi\left(w_{B}(\tilde{X}), \widetilde{x}_{1}, \ldots, \widetilde{x}_{n}\right)$ and Equation (5.2) is equivalent to

$$
\varphi\left(E\left[w_{B}(\tilde{X})\right], x_{1}, \ldots, x_{n}\right) \leq E\left[\varphi\left(w_{B}(\widetilde{X}), \widetilde{x}_{1}, \ldots, \widetilde{x}_{n}\right)\right] .
$$

The validity of Equation (5.3) for all $\widetilde{X}$ is equivalent, by Jensen's inequality, to the convexity of the function $\varphi$.

$(2) \Leftrightarrow(3):$ We know that $(2)$ is equivalent to $\Phi \equiv\left[\varphi_{i j}\right]_{i, j=0, \ldots, n}$ semi-definite positive. Letting $\Gamma$ (resp. $\Delta)$ denote $w_{A}$ (resp. $\left.w_{B}\right)$, we have $\varphi\left(y, x_{1}, \ldots, x_{n}\right) \equiv$ $\Gamma\left[(\Delta)^{-1}\left(y, x_{1}, \ldots, x_{n}\right), x_{1}, \ldots, x_{n}\right]$ and $R_{i j}=\frac{\Delta_{i j}}{\Delta_{0}}-\frac{\Gamma_{i j}}{\Gamma_{0}}$. By direct differentiation, we get $\varphi_{00}=\frac{\partial}{\partial y}\left(\frac{\Gamma_{0}\left(\Delta^{-1}(y, x), x\right)}{\Delta_{0}\left(\Delta^{-1}(y, x), x\right)}\right)=\frac{-\Gamma_{0}}{\left(\Delta_{0}\right)^{2}}\left[\frac{\Delta_{00}}{\Delta_{0}}-\frac{\Gamma_{00}}{\Gamma_{0}}\right]=\frac{-\Gamma_{0}}{\left(\Delta_{0}\right)^{2}} R_{00}$, hence $\varphi_{00}>0$ if and only if $R_{00}>0$. For $i \geq 1$, subtracting $\varphi_{i 0} / \varphi_{00}$ times the first row of $\Phi$ from the $i$ th row, and then for $j \geq 1$, subtracting $\varphi_{0 j} / \varphi_{00}$ times the first column of $\Phi$ from the $j$ th column, we get the matrix $M=\left(\begin{array}{ll}\varphi_{00} & 0 \\ 0 & \varphi_{i j}-\frac{\varphi_{i 0} \varphi_{0 j}}{\varphi_{00}}\end{array}\right)$. The principal minors of $M$ are the same as those of $\Phi$. By direct differentiation, we get that

$$
\begin{aligned}
\varphi_{i j} & =\Gamma_{0}\left[-R_{i j}-\frac{\Delta_{i} \Delta_{j}}{\Delta_{0}^{2}} R_{00}+\frac{\Delta_{i}}{\Delta_{0}} R_{j 0}+\frac{\Delta_{j}}{\Delta_{0}} R_{0 i}\right] \\
\varphi_{i 0} & =\Gamma_{0}\left[\frac{\Delta_{i}}{\Delta_{0}^{2}} R_{00}-\frac{1}{\Delta_{0}} R_{i 0}\right], \varphi_{j 0}=\Gamma_{0}\left[\frac{\Delta_{j}}{\Delta_{0}^{2}} R_{00}-\frac{1}{\Delta_{0}} R_{j 0}\right],
\end{aligned}
$$

and $M=-\Gamma_{0}\left(\begin{array}{ll}\frac{R_{00}}{\left(\Delta_{0}\right)^{2}} & 0 \\ 0 & R_{i j}-\frac{R_{i 0} R_{0 j}}{R_{00}}\end{array}\right)$. Since $\left(-\Gamma_{0}\right)>0$, it follows that all the principal minors of $M$ have the same sign as those of the same order of $R$. Hence $\Phi$ is positive semi-definite if and only if $R$ is positive semi-definite. 


\subsection{Proof of Proposition 5}

Let us first prove $(1) \Leftrightarrow(2)$ : When $X$ and $\widetilde{e}$ are given and when $\Psi(X, \widetilde{e}, w)$ is decreasing in $x_{0}$, the function $x_{0} \rightarrow x_{0}-\Psi(X, \widetilde{e}, w)$ is increasing and we denote by $f\left(x_{0} ; x_{1}, \ldots, x_{n}, \widetilde{e}_{0}, \ldots, \widetilde{e}_{n}\right)$ its inverse. By definition of $\Psi(X, \widetilde{e}, w)$ we have then

$$
w(X)=E\left[w\left(f\left(x_{0} ; x_{1}, \ldots, x_{n}, \widetilde{e}_{0}, \ldots, \widetilde{e}_{n}\right)+\widetilde{e}_{0}, \tilde{x}_{1}, \ldots, \tilde{x}_{n}\right)\right]
$$

and we have then that $f\left(x_{0} ; x_{1}, \ldots, x_{n}, \widetilde{e}_{0}, \ldots, \widetilde{e}_{n}\right)=x_{0}+\Psi^{*}(X, \widetilde{e}, w)$. Since $\Psi(X, \widetilde{e}, w)$ is decreasing in $x_{0}, x_{0}-\Psi(X, \widetilde{e}, w)$ increases faster than $x_{0}$ and $f\left(x_{0} ; x_{1}, \ldots, x_{n}, \widetilde{e}_{0}, \ldots, \widetilde{e}_{n}\right)$ increases in $x_{0}$ at a slower rate than $x_{0}$ which gives that $\Psi^{*}(X, \widetilde{e}, w)$ decreases in $x_{0}$. It is easy to check that a similar argument gives that $\Psi^{*}(X, \widetilde{e}, w)$ increases in $x_{0}$ when $\Psi(X, \widetilde{e}, w)$ increases in $x_{0}$.

We prove now that $(2) \Leftrightarrow(3)$. By definition of $g$, we have

$$
\frac{\partial u}{\partial y_{0}}\left(c, y_{1}, \ldots, y_{n}\right)=E\left[w\left(g\left(c ; x_{1}, \ldots, x_{n}, \widetilde{e}_{0}, \ldots, \widetilde{e}_{n}\right)+\widetilde{e}_{0}+\rho_{0}\left(y_{0}-c\right), \tilde{x}_{1}, \ldots, \tilde{x}_{n}\right)\right]
$$

and since the left term does not depend on $\tilde{e}$ we have

$$
\frac{\partial u}{\partial y_{0}}\left(c, y_{1}, \ldots, y_{n}\right)=w\left(g\left(c ; x_{1}, \ldots, x_{n}, 0, \ldots, 0\right)+\rho_{0}\left(y_{0}-c\right), x_{1}, \ldots, x_{n}\right)
$$

By definition of $\Psi^{*}(X, \widetilde{e}, w)$ we have

$$
\begin{aligned}
& w\left(g\left(c ; x_{1}, \ldots, x_{n}, 0, \ldots, 0\right)+\rho_{0}\left(y_{0}-c\right), x_{1}, \ldots, x_{n}\right) \\
= & E\left[w\left(g\left(c ; x_{1}, \ldots, x_{n}, 0, \ldots, 0\right)+\rho_{0}\left(y_{0}-c\right)+\widetilde{e}_{0}+\Psi^{*}(X, \widetilde{e}, w), \tilde{x}_{1}, \ldots, \tilde{x}_{n}\right)\right]
\end{aligned}
$$

with $X=\left(g\left(c ; x_{1}, \ldots, x_{n}, 0, \ldots, 0\right)+\rho_{0}\left(y_{0}-c\right), x_{1}, \ldots, x_{n}\right)$.

We have then

$$
\begin{aligned}
& E\left[w\left(g\left(c ; x_{1}, \ldots, x_{n}, e_{0}, \ldots, e_{n}\right)+\widetilde{e}_{0}+\rho_{0}\left(y_{0}-c\right), \tilde{x}_{1}, \ldots, \tilde{x}_{n}\right)\right] \\
= & E\left[w\left(g\left(c ; x_{1}, \ldots, x_{n}, 0, \ldots, 0\right)+\widetilde{e}_{0}+\rho_{0}\left(y_{0}-c\right)+\Psi^{*}(X, \widetilde{e}, w), \tilde{x}_{1}, \ldots, \tilde{x}_{n}\right)\right]
\end{aligned}
$$

and since $w$ is decreasing in $x_{0}$ this gives

$$
g\left(c ; x_{1}, \ldots, x_{n}, 0, \ldots, 0\right)+\Psi^{*}(X, \widetilde{e}, w)=g\left(c ; x_{1}, \ldots, x_{n}, \widetilde{e}_{0}, \ldots, \widetilde{e}_{n}\right) .
$$

Differentiating this equation with respect to $c$ gives

$$
\begin{aligned}
& \frac{\partial g}{\partial c}\left(c ; x_{1}, \ldots, x_{n}, \widetilde{e}_{0}, \ldots, \widetilde{e}_{n}\right) \\
= & \frac{\partial g}{\partial c}\left(c ; x_{1}, \ldots, x_{n}, 0, \ldots, 0\right) \\
& +\left(\frac{\partial g}{\partial c}\left(c ; x_{1}, \ldots, x_{n}, 0, \ldots, 0\right)-\rho_{0}\right) \frac{\partial \Psi^{*}}{\partial x_{0}}(X, \widetilde{e}, w) .
\end{aligned}
$$


Differentiating Equation (5.4) with respect to $y_{0}$ gives

$$
\frac{\partial^{2} u}{\partial y_{0}^{2}}\left(c, y_{1}, \ldots, y_{n}\right)=\left(\frac{\partial g}{\partial c}\left(c ; x_{1}, \ldots, x_{n}, 0, \ldots, 0\right)-\rho_{0}\right) E\left[\frac{\partial w}{\partial x_{0}}(\widetilde{Z})\right]
$$

with $\widetilde{Z}=\left(g\left(c ; x_{1}, \ldots, x_{n}, \widetilde{e}_{0}, \ldots, \widetilde{e}_{n}\right)+\widetilde{e}_{0}+\rho_{0}\left(y_{0}-c\right), \tilde{x}_{1}, \ldots, \tilde{x}_{n}\right)$.

Since $u$ is concave and $w$ decreasing, we have $\frac{\partial g}{\partial c}\left(c ; x_{1}, \ldots, x_{n}, 0, \ldots, 0\right)-\rho_{0}>0$. If $\Psi^{*}(X, \widetilde{e}, w)$ is decreasing in $x_{0}$, Equation (5.5) gives us that

$$
\frac{\partial g}{\partial c}\left(c ; x_{1}, \ldots, x_{n}, \widetilde{e}_{0}, \ldots, \widetilde{e}_{n}\right)<\frac{\partial g}{\partial c}\left(c ; x_{1}, \ldots, x_{n}, 0, \ldots, 0\right) .
$$

The impact of the multidimensional risk is then towards a decrease of $\frac{\partial g}{\partial c}$. Since $g$ is the inverse of the consumption function, this means that the impact of the multidimensional risk is towards an increase of the marginal propensity to consume out of wealth. We have the opposite impact when $\Psi^{*}(X, \widetilde{e}, w)$ is increasing in $x_{0}$.

\subsection{Uncertain returns and partial MDRA}

We can motivate the propensity to save an additional amount in the presence of multidimensional rate of return risk with a basic preference towards harm disaggregation (see e.g. Chiu et al (2010) in the context of a single attribute). Let us define MDRA with risky harm as follows:

$$
[X-k \tilde{\rho} ; \tilde{X}] \succ[X ; \tilde{X}-k \tilde{\rho}],
$$

where, in each lottery, the outcomes have equal probability. The unique difference with MDRA lies in the fact that the harm $\tilde{\rho}$ is risky. We may also introduce the concept of partial MDRA with risky harm by considering the specific situation where $\widetilde{X}$ is of the form $Y+s \tilde{\rho}$ (and hence, $X=Y+s \rho$ ), that is to say the situation where the additional harm is fully correlated to the risk about $X$. The partial MDRA with risky harm is then defined by

$$
[Y+s \rho-k \tilde{\rho} ; Y+s \tilde{\rho}] \succ[Y+s \rho ; Y+(s-k) \tilde{\rho}]
$$

where, in each lottery, the outcomes have equal probability. In the case of expected utility, we have

$$
\frac{1}{2} E[u(Y+s \rho-k \tilde{\rho})]+\frac{1}{2} E[u(Y+s \tilde{\rho})]>\frac{1}{2} u(Y+s \rho)+\frac{1}{2} E[u(Y+(s-k) \tilde{\rho})] .
$$


For small $k$, this leads to

$$
\sum_{i=0}^{n} E\left[\tilde{\rho}_{i} \frac{\partial u}{\partial x_{i}}(Y+s \rho)\right]<\sum_{i=0}^{n} E\left[\tilde{\rho}_{i} \frac{\partial u}{\partial x_{i}}(Y+s \tilde{\rho})\right]
$$

or

$$
\sum_{i=0}^{n} \rho_{i} \frac{\partial u}{\partial x_{i}}(Y+s \rho)<\sum_{i=0}^{n} E\left[\tilde{\rho}_{i} \frac{\partial u}{\partial x_{i}}(Y+s \tilde{\rho})\right]
$$

which is equivalent to the convexity of the function $W(\rho)=\sum_{i=0}^{n} \rho_{i} \frac{\partial u}{\partial x_{i}}(Y+s \rho)$ in $\rho$, which is the same condition that we presented in section 3.3.2 for extra saving in the presence of multidimensional rate of return risk.

\section{References}

[1] Abel, A. B. (1990) Asset Prices under Habit Formation and Catching Up with the Joneses. American Economic Review papers and proceedings 80, $38-42$.

[2] Arrow, K. J. (1971) The Theory of Risk Aversion, in Essays in the Theory of Risk Bearing. Chicago: Markham.

[3] Becker, G. (1974) A Theory of Social Interactions. Journal of Political Economy. 82, 1063-1093.

[4] Bentham, J. (1789) Principles of Morals and Legislation. Oxford: Clarendon.

[5] Bui, P., Crainich D., Eeckhoudt L. (2005). Allocating health care resources under risk: Risk aversion and prudence matter. Health Economics 14, 10731077.

[6] Carroll C. (2009). Precautionary saving and the marginal propensity to consume out of permanent income, Journal of Monetary Economics 56, 780-790.

[7] Carroll C., Kimball, M. (1996). On the concavity opf the consumption function, Econometrica 64, 981-992.

[8] Carroll C., Kimball, M. (2008). Precautionary saving and precautionary wealth, The New Palgrave Dictionary of Economics, 2nd Ed., Eds. Steven N. Durlauf and Lawrence E. Blume. Palgrave Macmillan. 
[9] Chiu, W.H., Eeckhoudt, L., Rey, B. (2010). On relative and partial risk attitudes: Theory and Implications. Economic Theory, forthcoming.

[10] Courbage C., Rey B. (2007). Precautionary saving in the presence of other risks, Economic Theory 32, 417-424.

[11] Crainich, D., Eeckhoudt, L. (2007). On the Intensity of Downside Risk Aversion. Journal of Risk and Uncertainty 36; 267-76.

[12] Denuit, M., Eeckhoudt, L. (2010) Stronger measures of higher-order risk attitudes. Journal of Economic Theory 145, 2027-2036.

[13] Denuit, M., Eeckhoudt, L., Menegatti, M. (2011) Correlated Risks, Bivariate Utility and Optimal Choices. Economic Theory 46, 39-54.

[14] Drèze, J., Modigliani,F. (1972) Consumption Decisions under Uncertainty. Journal of Economic Theory, 5, 308-335.

[15] Duesenberry, J. S. (1949) Income, Saving, and the Theory of Consumer Behavior. Cambridge: Harvard University Press.

[16] Duncan, G. T. (1977). A Matrix Measure of Multivariate Local Risk Aversion,. Econometrica, 45 , 895-903.

[17] Eeckhoudt, L., Schlesinger, H. (1994). A Precautionary Tale of Prudence and Risk Aversion, Models and Experiments on Risk and Rationality, Eds. M. J. Machina and B. R. Munier, Dordrecht/Boston: Kluwer Academic Publishers.

[18] Eeckhoudt, L., Schlesinger, H. (2006). Putting risk in its proper place. American Economic Review 96, 280-289.

[19] Eeckhoudt, L., Schlesinger, H. (2008) Changes in risk and the demand for saving. Journal of Monetary Economics, 55, 1329-1336.

[20] Eeckhoudt, L., Rey, B., Schlesinger, H. (2007). A good sign for multivariate risk taking. Management Science 53, 117-124.

[21] Floden, M. (2006). Labor supply and saving under uncertainty. Economic Journal 116, 721-737.

[22] Gali, J. (1994) Keeping up with the Joneses: consumption externalities, portfolio choice and asset prices. Journal of Money, Credit and Banking 26, 1-8. 
[23] Gollier, C. (2001) The Economics of Risk and Time, M.I.T. Press.

[24] Jindapon, P., Neilson, W.S. (2007) Higher-order generalizations of ArrowPratt and Ross risk aversion: A comparative statics approach, Journal of Economic Theory 136, 719-728.

[25] Hoel M. (2003) Allocating health care resources when people are risk averse with respect to life time. Health Economics 12, 601-608.

[26] Karni, E. (1979). On multivariate risk aversion. Econometrica 47, 1391-1401.

[27] Keenan, D., Snow, A. (2009). Greater Downside Risk Aversion in the Large. Journal of Economic Theory, 144; 1092-1101.

[28] Kimball, M. (1990a). Precautionary saving and the marginal propensity to consume. NBER working paper 3403.

[29] Kimball, M. (1990b) Precautionary saving in the small and in the large. Econometrica, 58, 58-73.

[30] Kimball, M. (1993) Standard risk aversion. Econometrica. 61, 589-611.

[31] Kimball, M., Weil, P. (2009) Precautionary saving and consumption smoothing across time and possibilities. Journal of Money, Credit, and Banking 41, $245-284$.

[32] Kreps, D. M. Porteus,E.L., (1978) Temporal resolution of uncertainty and dynamic choice Theory. Econometrica, 46, 185-200.

[33] Kihlstrom, R. E., Mirman, L.J., (1974) Risk aversion with many commodities. Journal of Economic Theory, 8, 361-368.

[34] Leland, H. E. (1968) Saving and uncertainty: The precautionary demand for saving. Quarterly Journal of Economics, 82, 465-73.

[35] Menegatti, M. (2009). Precautionary saving in the presence of other risks: A comment. Economic Theory 39, 473-476.

[36] Menezes, C., Geiss, C., Tressler, J. (1980) Increasing downside risk, American Economic Review 70, 921-932. 
[37] Modica, S., Scarsini, M. (2005) A note of comparative downside risk aversion, Journal of Economic Theory 122 (2005), 267-271.

[38] Nocetti D., Smith, W.T. (2011a). Price uncertainty, saving, and welfare. Journal of Economic Dynamics and Control 35, 1139-1149.

[39] Nocetti D., Smith, W.T. (2011b). Precautionary saving and endogenous labor supply with and without intertemporal expected utility. Journal of Money, Credit, and Banking, Forthcoming.

[40] Paroush, J. (1975) Risk Premium with Many Commodities. Journal of Economic Theory 11, 283-286.

[41] Pratt, J.W. (1964) Risk aversion in the small and in the large. Econometrica $32,122-136$.

[42] Sandmo, A. (1970) The effect of uncertainty on saving decisions. Review of Economic Studies, 37, 353-60.

[43] Stiglitz, J. E. (1969) Behavior Towards Risk with Many Commodities. Econometrica, 31, 660-667.

[44] Veblen, T. (1899) Theory of the Leisure Class: An Economic Study in the Evolution of Institutions. New York: Macmillan. 